Angiogenesis plays an essential role in tumor growth and metastasis and is a promising target for cancer therapy. Vascular endothelial growth factor (VEGF) is a key regulator of angiogenesis. The present study was designed to determine the role of VEGF in tumor growth and metastasis. The sequences for the VEGF gene were cloned into expression plasmids and then transfected into melanoma B16 cells. Overexpression of VEGF transfected with expression plasmids or given exogenous VEGF and epidermal growth factor (EGF) significantly enhanced tumor cell proliferation, migration, and invasion. Tumor growth and metastasis of melanoma B16 cells transfected with VEGF plasmid were significantly promoted compared with those of cells administered with exogenous VEGF or EGF. These results indicated that VEGF can be an effective antiangiogenic strategy for melanoma.

Key words: VEGF, B16 cells, EGF.

\section{Promoting melanoma growth and metastasis by enhancing VEGF expression}

\author{
Chun-sheng Ni ${ }^{1+\#}$, Bao-cun Sun ${ }^{1,2, \#}$, Xue-yi Dong ${ }^{1}$, Tao Sun ${ }^{1}$, Nan Zhao ${ }^{1}$, \\ Yan-rong Liu ${ }^{1}$, Qiang $\mathrm{Gu}^{1}$ \\ ${ }^{1}$ Department of Pathology, Tianjin Medical University, Tianjin, China \\ 2Department of Pathology, Tianjin Cancer Hospital, Tianjin Medical University, Tianjin, \\ China \\ \#These authors contributed equally to this work.
}

\section{Introduction}

Angiogenesis is an important step in the outgrowth of a primary tumor. Dissemination, progression, and metastasis of a hematogenous tumor are known to be dependent on angiogenesis. Many potential angiogenic factors have been identified, including basic fibroblast growth factor, vascular endothelial growth factor (VEGF), and platelet-derived endothelial cell growth factor [1-3]. Of these factors, VEGF is perhaps the most prominent, and its actions on the vasculature, including the stimulation of endothelial cell growth, motility, and blood vessel permeability, have been extensively studied. The function of VEGF in other cell types is mostly unknown [4-10].

Melanoma is the most common skin cancer in both men and women, accounting for about $5 \%$ of all new cancer cases in the United States. The incidence of melanoma is rising steadily, and the number of cases worldwide has doubled in the past 20 years [1]. Total VEGF levels have been associated with melanoma progression [11]. However, the possible autocrine and/or paracrine mechanisms remain unknown.

In the current study, we report that overexpression of VEGF transfected with expression plasmids has a stronger effect on tumor cell proliferation, migration, and invasion in melanoma. These findings suggested that intracellular VEGF may play a more important role in promoting melanoma growth and metastasis.

\section{Material and methods}

\section{Cell culture}

The melanoma cell line B16 (Laboratory of Cell Biology, Tianjin Medical School, Tianjin, China) was maintained in RPMI 1640 medium supplemented with 10\% fetal bovine serum, $100 \mu \mathrm{g} / \mathrm{ml}$ penicillin, and $100 \mu \mathrm{g} / \mathrm{ml}$ streptomycin. Cell cultures were determined to be free of Mycoplasma contamination by routine testing.

\section{Construction of VEGF expression plasmids}

We selected sequences as reported by Elbashir et al. [12]. We used the following procedure to design the VEGF sequences: search for sequence 5'-AA(N19) or 5'-NA(N19), where $\mathrm{N}$ is any nucleotide, in the intended mRNA sequence and use only those sequences that occur within an open reading frame, preferably 50 to 100 nt downstream of the start codon, and show $47 \%$ or $52 \% \mathrm{G} / \mathrm{C}$ content. Primers containing the sense sequence, $9 \mathrm{bp}$ loop sequence, and RNA polymerase III terminator sequence were created with BamHI and HindIII restric- 
tion sites on the 5' and 3' ends, respectively. These primers were annealed and inserted into pGenesil-1 (Gene Biotechnology) downstream of the H1 RNA polymerase III promoter, following the manufacturer's instructions. The resultant plasmids containing sequences and negative control sequences were labeled p-VEGF (VEGF-expressing plasmids) and control, respectively.

\section{Western blot analysis}

For the analysis of intracellular VEGF protein levels, untransfected and transfected melanoma B16 cells were cultured in $100 \mathrm{~mm}$ dishes. When the cells reached $80 \%$ confluence, cell lysates were collected, and protein concentrations were determined using the BCA Protein Assay Reagent Kit (Pierce, Rockford, IL). The protein samples $(50 \mu \mathrm{g})$ were boiled for $3 \mathrm{~min}$ before being loaded onto a 7.5\% SDS-polyacrylamide gel. After electrophoresis, the proteins were transferred to a PVDF membrane (Amersham, Piscataway, NJ). The membranes were probed with primary antibody followed by peroxidase-conjugated secondary antibody (1 : 2,000; Santa Cruz Biotechnology, USA) and visualized by an enhanced chemiluminescence detection system (Amersham) according to the manufacturer's instructions. The antibodies of VEGF (mouse monoclonal antibody, clone number: C-1, catalogue number: sc-7269, 1: 200) and $\beta$-actin (rabbit polyclonal antibody, sc-1616, $1: 200$ ) were purchased from Santa Cruz Biotechnology.

\section{MTT assay}

Cell proliferation was measured by MTT assay. Melanoma B16 cells in the negative control group, the group transfected with $p-V E G F$, and the group given exogenous VEGF, EGF (epidermal growth factor), and $\mathrm{CoCl}_{2}$ [cobalt(II) chloride] were seeded in 24-well plates at a density of $1 \times 10^{4}$ cells/well. The EGF and $\mathrm{CoCl}_{2}$ treated groups were used for the reference and comparison of the effects of the exogenous VEGF and p-VEGF groups as both EGF and hypoxia (which can be mimicked by $\mathrm{CoCl}_{2}$ in vitro) were reported to promote the development and progression of melanoma [13, 14]. After 12, 24, 36, 48, and $60 \mathrm{~h}$ of incubation, $200 \mu \mathrm{l}$ of $5 \mathrm{mg} / \mu \mathrm{l}$ solution of MTT (Sigma, Guangzhou, China) in PBS was added to each well. The plates were then incubated for $4 \mathrm{~h}$ at $37^{\circ} \mathrm{C}$. The precipitate was then solubilized in 100\% dimethylsulfoxide (Sigma), $100 \mu \mathrm{l} /$ well, and shaken for $15 \mathrm{~min}$. Absorbance of each well was measured on a microplate reader at a wavelength of $492 \mathrm{~nm}$. All experiments were done in quadruplicate.

\section{Wound healing assay}

Wound healing assays were performed with 12 -well plates. Cell motility was assessed by measuring the movement of cells into a scarped, acellular area created by a $200 \mu$ l pipette tube (time 0); the speed of wound closure was monitored at various time points. The ratio of the distance to $\mathrm{O} h$ of the wound was measured. Each experiment was repeated in triplicate, and the mean values (mean \pm SE) were presented.

\section{Gelatin zymography}

Gelatin zymography was used to examine the levels of MMP-2 and MMP-9 activity. Serum-free conditioned media were used as a control. All media were collected and subjected to SDS-PAGE using $0.01 \% \mathrm{w} / \mathrm{v}$ gelatin with $10 \%$ polyacrylamide gel. After electrophoresis, the gels were equilibrated in $50 \mathrm{mM}$ Tris- $\mathrm{HCl}$ ( $\mathrm{pH}$ 7.5) with 2.5\% Triton X-100 for $30 \mathrm{~min}$ at room temperature. Subsequently, they were incubated in $50 \mathrm{mM}$ Tris- $\mathrm{HCl}(\mathrm{pH} 7.5), 10 \mathrm{mM} \mathrm{CaCl}_{2}, 150 \mathrm{mM} \mathrm{NaCl}$, $1 \mathrm{mM} \mathrm{ZnCl}$, and $0.02 \% \mathrm{NaN}_{3}$ for $20 \mathrm{~h}$ at $37^{\circ} \mathrm{C}$. These were stained with Coomassie R250 and destained until the wash became clear, with apparent cleared zones associated with MMP activity. The zymogram was digitized, and the amount of clearing associated with MMP-2 and MMP-9 activity was determined using the Gene Genius Super system. The values were calculated by densitometry.

\section{Statistical analysis}

All data in the study were evaluated with SPSS 13.0 (SPSS, Chicago, IL). All results were expressed as means \pm SD. Differences were considered significant at $p<0.05$. The significant group was marked with an asterisk in the figures.

\section{Results}

\section{Effects of $p$-VEGF on the expression of VEGF}

p-VEGF and a negative control plasmid were constructed using the vector. After the $p$-VEGFs are successfully transfected into B16 cells, the VEGF protein levels can be detected. As shown in Fig. 1, p-VEGFs significantly promoted VEGF expression in the cell lines as measured. Subsequent experiments focused on the $p$-VEGF that was most effective in promoting VEGF expression (Fig. 1).

\section{Effects of $p$-VEGF on tumor cell proliferation}

The biological effects of the $p$-VEGFs were first determined using cell proliferation assays. As shown in Fig. 2A, the proliferation of cells transfected with $p$-VEGF was significantly promoted at day 2 ( $p<0.01$, compared with the controls), whereas negative control melanoma B16 cells showed little difference with the cells given exogenous VEGF, EGF, and $\mathrm{CoCl}_{2}$ over the entire experimental period $(p>0.05)$. VEGF was also found to have an effect on cell culture (Fig. 2B).

\section{Effects of p-VEGF on tumor cell migration}

As shown in Fig. 3, the migration distance of the melanoma B16 cells, the cells transfected with p-VEGF, and the cells given exogenous VEGF, EGF, and $\mathrm{CoCl}_{2}$ was 0.33 ,

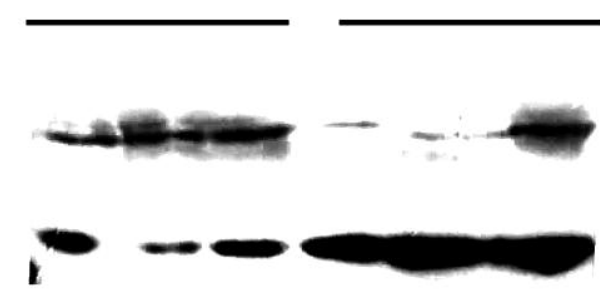

Fig. 1. Expression of VEGF in cells transfected with $p$-VEGF and given exogenous VEGF. Western blot analysis was used to measure the amount of VEGF in cells transfected with negative control plasmid (C), p-VEGF (P), and cells given exogenous VEGF (V) after treatment for $48 \mathrm{~h}$ and $72 \mathrm{~h}$. 
A

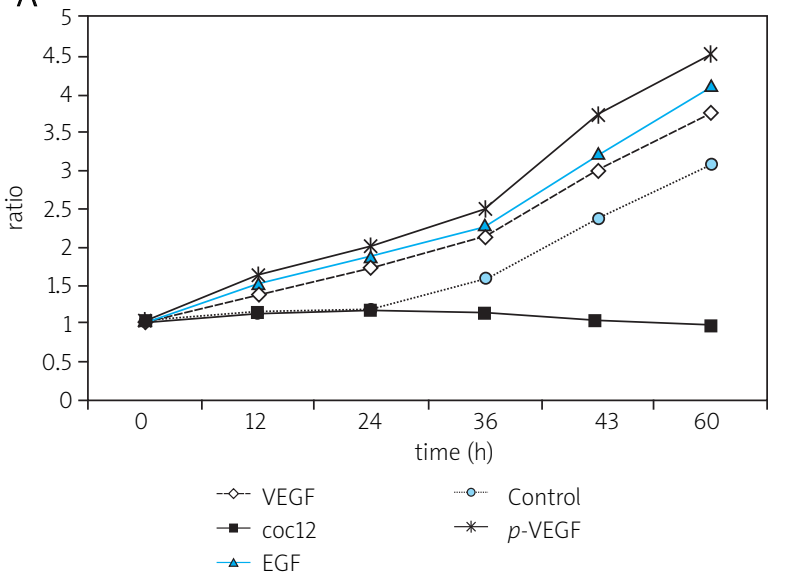

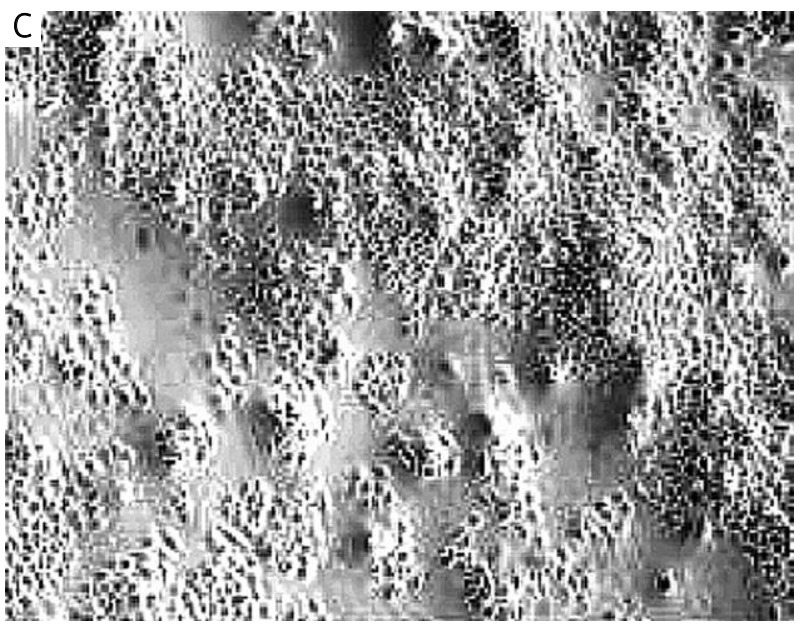

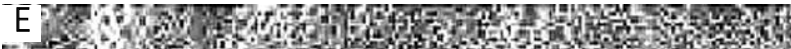

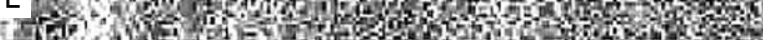

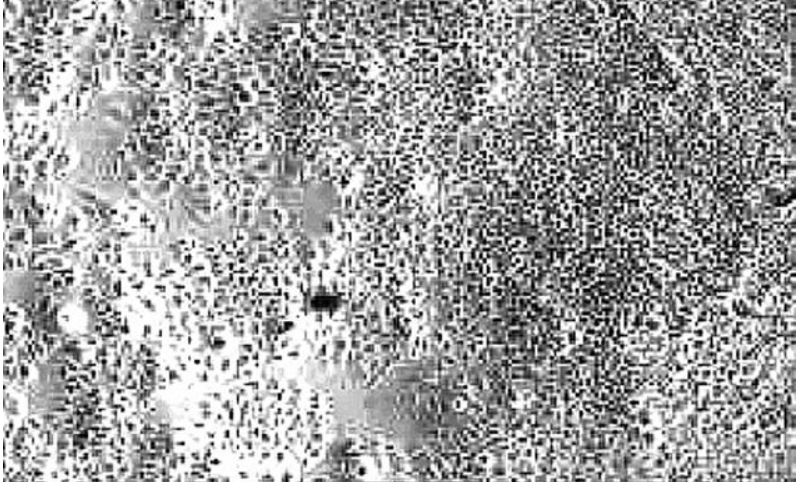

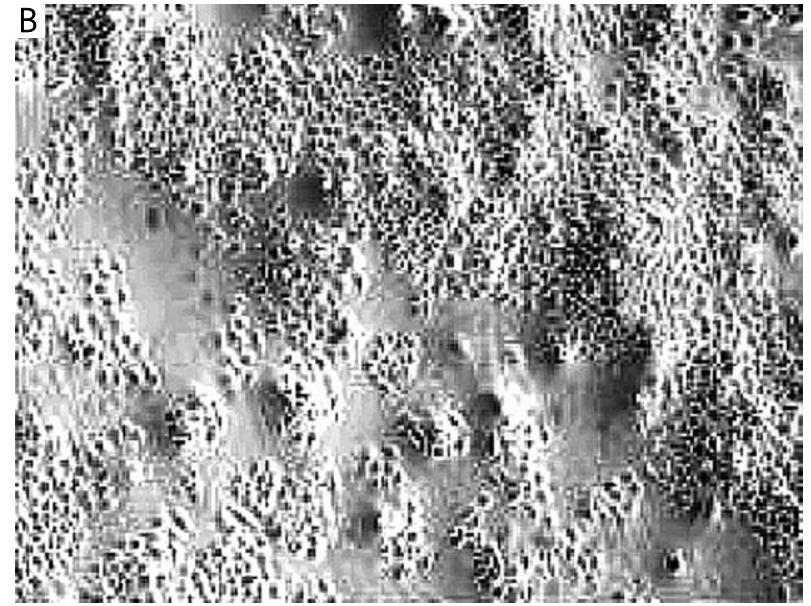
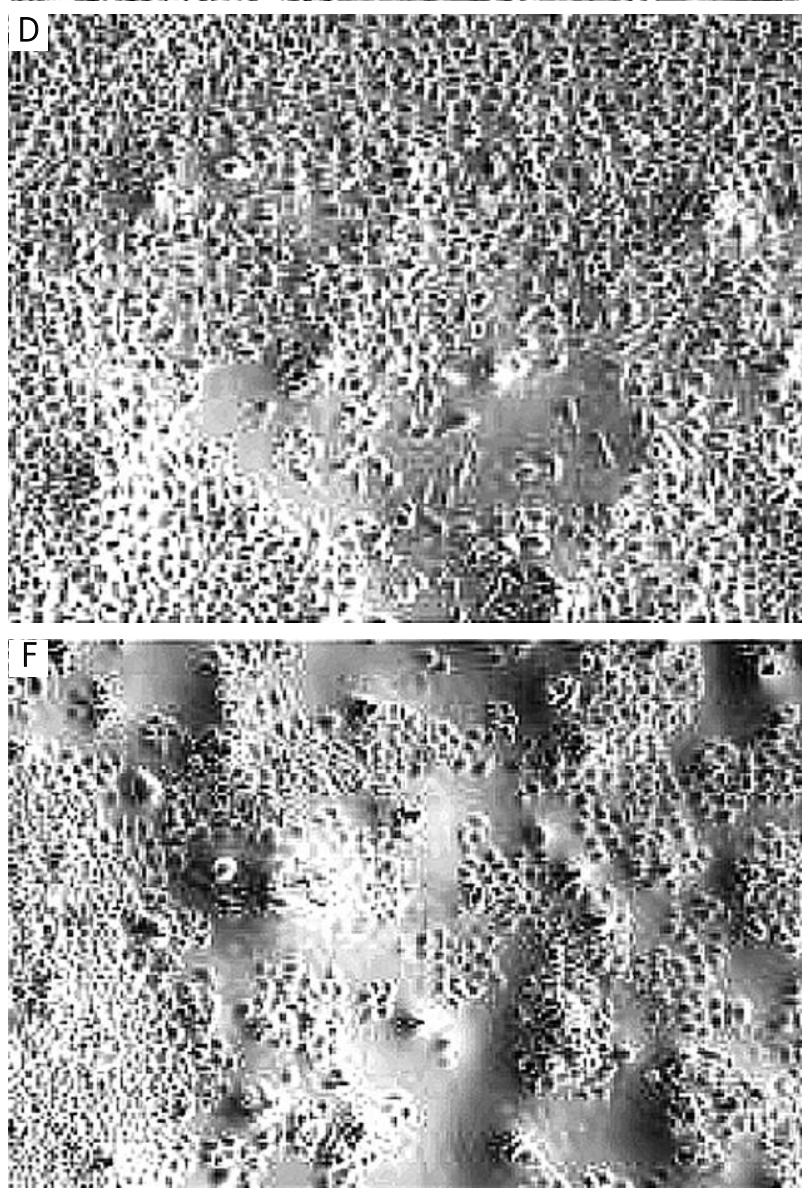

Fig. 2. A) Effects of $p$-VEGF on tumor cell proliferation as measured by MTT assay $(p<0.01)$. B) VEGF transfection was used to construct plasmids expressing VEGF. The melanoma B16 cells, the cells transfected with $p$-VEGF, and the cells given exogenous VEGF, $E G F$, and $\mathrm{CoCl} 2$ can be easily identified by microscopy

$0.15,0.3,0.22$, and $0.27 \mathrm{~mm}$, respectively. These results suggested that the migration of $p$-VEGF was significantly promoted $(p<0.01)$, whereas others showed little difference $(p>0.05)$.

\section{Effects of $p$-VEGF on tumor cell invasion}

An important function of MMP-2 in tumor invasion is its capability to degrade the extracellular matrix and basement membranes. The promotion of MMP-2 activity in B16 cells by the potent MMP-2-specific promoter VEGF significantly induced the invasiveness of the cells (Fig. 4). The results of gelatin zymography suggested that altered VEGF activity directly affected the invasiveness of melanoma cells.

\section{Discussion}

VEGF-A is one of the most important angiogenic factors. Its role in angiogenesis and tumor development, growth, and metastasis has been well documented. When secreted by 
A
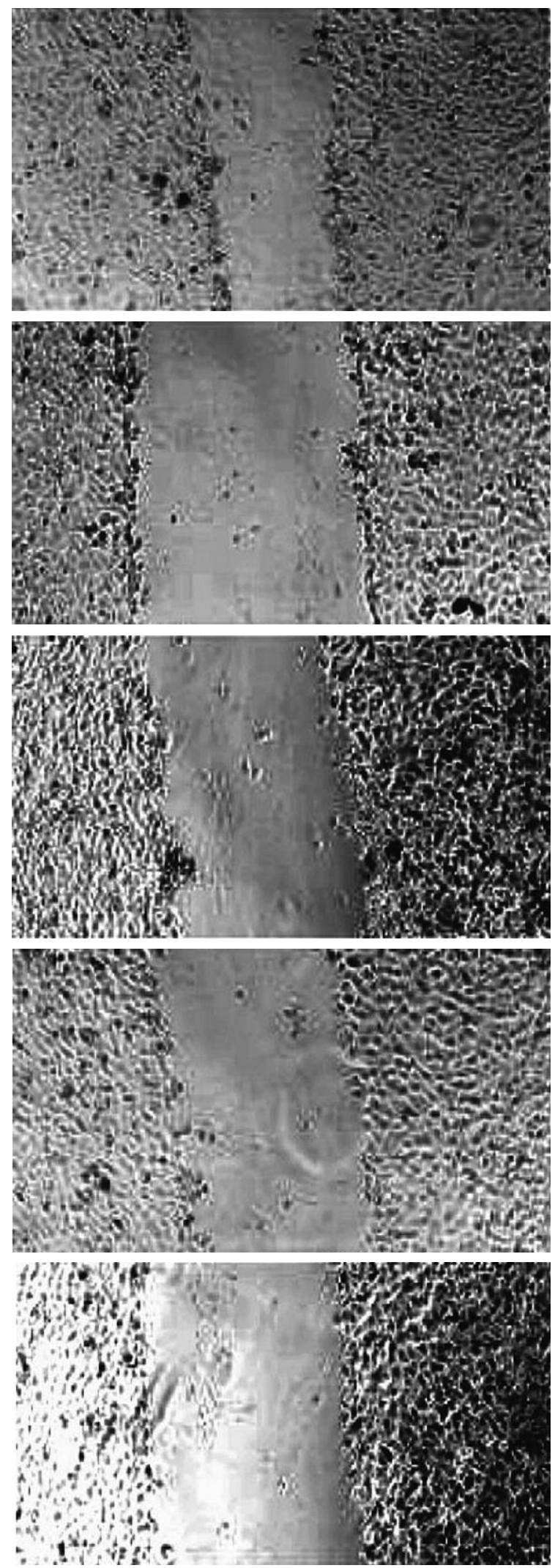

$24 \mathrm{~h}$

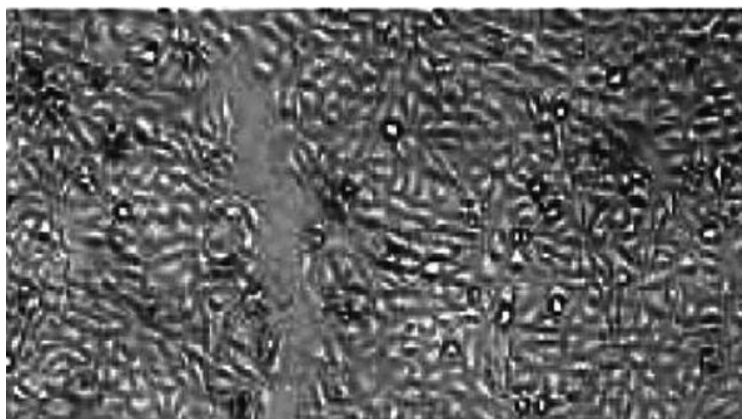

Control
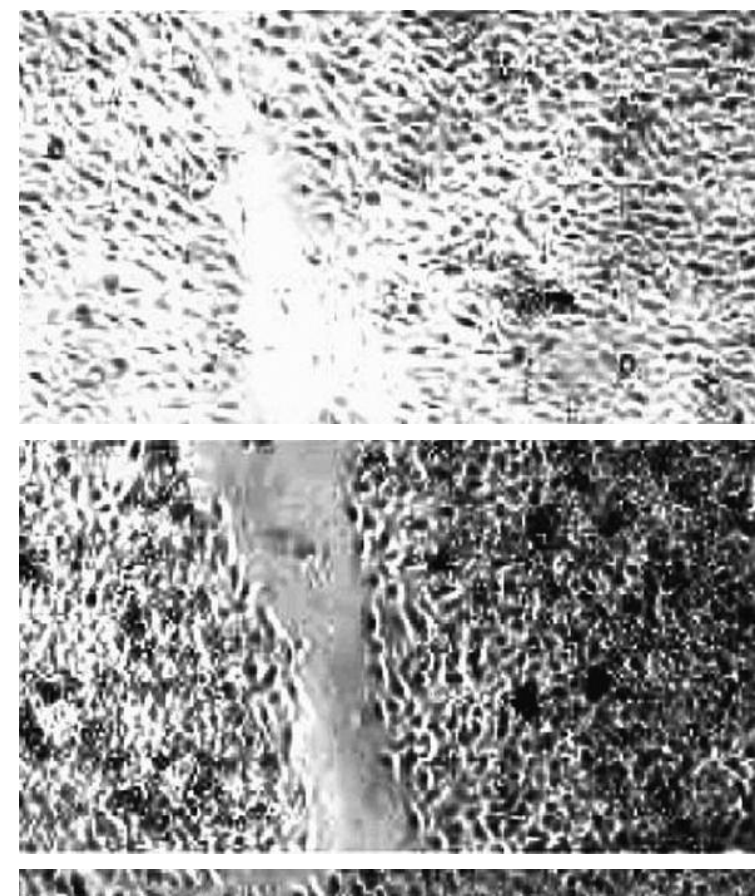

Bswers Q.

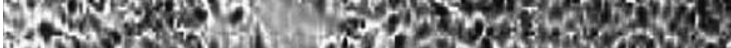

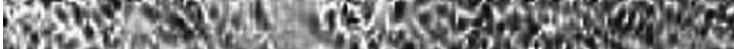

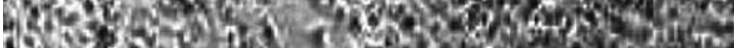

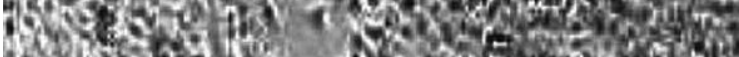

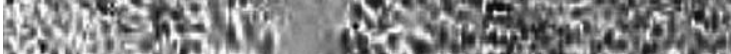

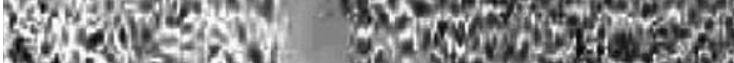

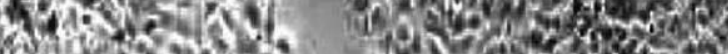

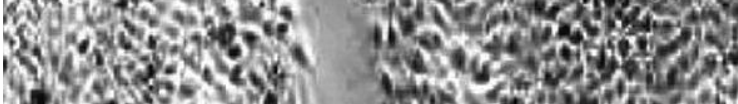
-VEGF

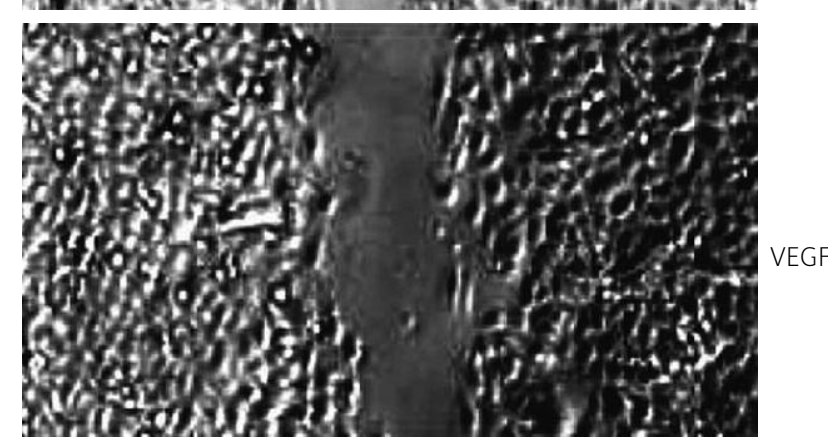

Fig. 3. Effects of $p$-VEGF on tumor cell migration $(p<0.01)$. Figure $3 A$ shows representative images of the wound region of B16 melanoma cells in different treatment groups $0 \mathrm{~h}$ and $24 \mathrm{~h}$ after wounding. Original magnification, $\times 40$. Figure $3 \mathrm{~B}$ (on the next page) shows the migration distance ratio to $0 \mathrm{~h}$ in different groups; the cells transfected with $p$-VEGF migrated more rapidly than the other groups $(p<0.01)$ 
B

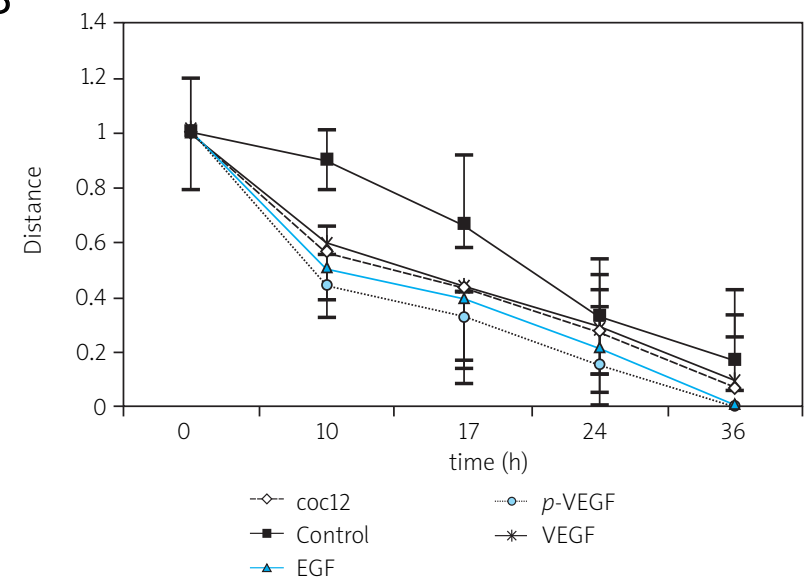

Fig. 3. (cont.) Effects of $p$-VEGF on tumor cell migration $(p<0.01$ ). Figure $3 A$ shows representative images of the wound region of B16 melanoma cells in different treatment groups $0 \mathrm{~h}$ and $24 \mathrm{~h}$ after wounding. Original magnification, $\times 40$. Figure $3 \mathrm{~B}$ shows the migration distance ratio to $0 \mathrm{~h}$ in different groups; the cells transfected with $p$-VEGF migrated more rapidly than the other groups $(p<0.01)$

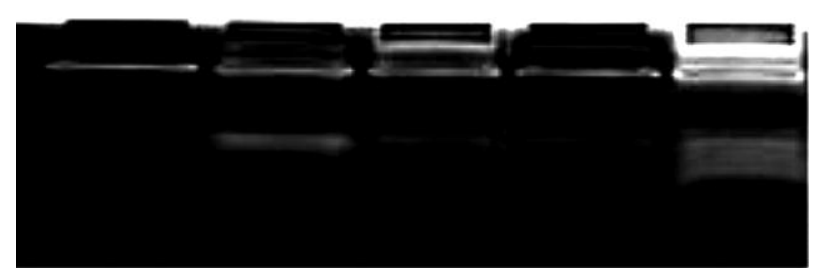

Fig. 4. Role of VEGF in B16 cells by gelatin zymography and MMP-2 activity assays were determined as described in $42 \mathrm{~h}$. More activities can be detected in B16 melanoma cells after transfection with $p$-VEGF

tumor cells, it stimulates proliferation of endothelial cells in a paracrine manner [15]. Although endothelial cells are the primary targets of VEGF, several studies have also reported its mitogenic effects on certain nonendothelial cells such as retinal pigment epithelial cells [16], pancreatic duct cells [17], and Schwann cells [18], as well as on cancer cells, including breast cancer [19], prostate cancer [20], and gastric adenocarcinoma [21]. These findings have led us to hypothesize that an autocrine loop exists, whereby VEGF stimulates tumor growth not only by interacting with endothelial cells but also by binding directly to the VEGF receptor (VEGFR) on tumor cells.

The present study demonstrated that plasmids cloned and transfected into tumor cells successfully promoted the expression and secretion of VEGF in melanoma B16 cells, leading to potent promotion of tumor cell proliferation, migration, and invasion in vitro. These findings not only demonstrated that VEGF played a critical role in melanoma cell proliferation, migration, and invasion but also suggested that a VEGF-mediated autocrine loop was a significant factor affecting tumor growth and metastasis.

Recent reports by Detwiller et al. [4] and Guan et al. [5] demonstrated that siRNA-targeting VEGF decreased sarcoma growth in vivo but had no effect on cellular proliferation in vitro. In the present study, we found that the VEGF plasmids cloned and transfected promoted not only the proliferation of B16 cells but also their capability to migrate and invade. The effects on proliferation, migration, and invasion appeared to be a direct effect of the increased production of VEGF by these cells. Our findings and those of previous studies $[22,23]$ support the idea that there may be a VEGFdirected autocrine loop directly affecting colon cancer cell growth and function. Studies have suggested that the mechanisms of VEGF/VEGFR interaction may involve the cyclooxygenase-2 inhibitor, but the specific mechanisms of VEGF/VEGFR interaction in both endothelial and tumor cells remain unclear. More studies are needed to delineate the signaling pathways mediated by VEGFRs.

In considering increased production of VEGF as a therapeutic tool, the methods of delivery must be considered because the efficacy and mode of delivery of siRNA vary considerably [24]. Chemically or enzymatically synthesized siR$N A$ is costly and has been shown to have a relatively short half-life, with only transient inhibition of target genes [25]. These and other problems have been addressed by changes in the delivery of RNAi. For example, repeated administration of siRNA can compensate for the reagent's short half-life. In addition, the use of ligand-directed nanoparticles has shown promise in addressing other RNAi issues such as cellular uptake, nonspecific immune stimulation, and limited stability [26]. The present study corroborates other studies [27, 28] that highlight another technique: the use of plasmid and viral vectors to produce siRNA using the polymerase III promoter. This approach may facilitate more efficient siRNA delivery and can theoretically induce stable gene silencing.

Even with a nearly promoting expression of VEGF protein secretion in vitro, B16 cells with $p$-VEGF were still not used in mice. Further, there may be several additional mechanisms involved in angiogenesis which are stimulated in VEGF-promoted/silenced tumors. For instance, tumors may induce surrounding stromal cells to secrete VEGF. Tumors derived from VEGF-null embryonic stem cells show that VEGF-A from tumor stroma can support tumor vascularization. VEGF-A is generated as multiple isoforms of two families, the pro-angiogenic family and the anti-angiogenic family. VEGF-165 and VEGF-165b respectively were the most studied isoforms. Inhi- 
bition of VEGF-165 has been seen as a new anticancer therapy by targeting microvasculature [29, 30].

Perhaps RNAi targeting multiple angiogenic factors can completely abrogate new blood vessel formation and tumor growth.

In summary, the present study demonstrated that the vector-mediated transfection of VEGF successfully promoted the expression of VEGF in in vitro models of melanoma, leading to several enhanced tumor activities such as promoting effects on cell proliferation, migration, and invasion. These findings suggest that the anti-VEGF approach can be an effective therapeutic strategy for melanoma. Therefore, the present study provides a basis for this approach in additional animal models and in human clinical trials.

\section{Acknowledgement}

This work was supported by a grant from a Key Project of the National Natural Science Foundation of China (No. 30830049), a Project of the National Natural Science Foundation of China (No. 81173091), and a Project of the Natural Science Foundation of Tianjin (No. 09JCYBJC10700).

The authors declare no conflict of interest.

\section{References}

1. Jemal A, Siegel R, Ward E, Hao Y, Xu J, Thun MJ. Cancer statistics, 2009 CA Cancer J Clin 2009; 59: 225-49.

2. Leung DW, Cachianes G, Kuang WJ, Goeddel DV, Ferrara N. Vascular endothelial growth factor is a secreted angiogenic mitogen. Science 1989; 246: 1306-9.

3. Takahashi Y, Bucana CD, Liu W, Yoneda J, Kitadai Y, Cleary KR, Ellis LM. Platelet-derived endothelial cell growth factor in human colon cancer angiogenesis: role of infiltrating cells. J Natl Cancer Inst 1996; 88: 1146-51.

4. Detwiller KY, Fernando NT, Segal NH, Ryeom SW, D'Amore PA, Yoon SS. Analysis of hypoxia-related gene expression in sarcomas and effect of hypoxia on RNA interference of vascular endothelial cell growth factor A. Cancer Res 2005; 65: 5881-9.

5. Guan H, Zhou Z, Wang H, Jia SF, Liu W, Kleinerman ES. A small inter fering RNA targeting vascular endothelial growth factor inhibits Ewing's sarcoma growth in a xenograft mouse model. Clin Cancer Res 2005; 11: 2662-9.

6. Suzuki K, Hayashi N, Miyamoto Y, et al. Expression of vascular permeability factor/vascular endothelial growth factor in human hepatocellular carcinoma. Cancer Res 1996; 56: 3004-9.

7. Ellis LM, Takahashi Y, Fenoglio CJ, Cleary KR, Bucana CD, Evans DB. Ves sel counts and vascular endothelial growth factor expression in pancreatic adenocarcinoma. Eur J Cancer 1998; 34: 337-40.

8. Tomisawa M, Tokunaga T, Oshika Y, et al. Expression pattern of vascular endothelial growth factor isoform is closely correlated with tumour stage and vascularisation in renal cell carcinoma. Eur J Cancer 1999; 35: 133-7.

9. Sowter HM, Corps AN, Evans AL, Clark DE, Charnock-Jones DS, Smith SK Expression and localization of the vascular endothelial growth factor fam ily in ovarian epithelial tumors. Lab Invest 1997; 77: 607-14.

10. Guidi AJ, Abu-Jawdeh G, Tognazzi K, Dvorak HF, Brown LF. Expression of vascular permeability factor (vascular endothelial growth factor) and its receptors in endometrial carcinoma. Cancer 1996; 78: 454-60.

11. Ascierto PA, Leonardi E, Ottaiano A, Napolitano M, Scala S, Castello G. Prognostic value of serum VEGF in melanoma patients: a pilot study. Anticancer Res 2004; 24: 4255-8.

12. Elbashir SM, Harborth J, Weber K, Tuschl T. Analysis of gene function in somatic mammalian cells using small interfering RNAs. Methods 2002; 26: 199-213.
13. Shahbazi M, Pravica V Nasreen N, et al. Association between functional polymorphism in EGF gene and malignant melanoma. Lancet 2002; 359: 397-401.

14. Rofstad EK, Rasmussen H, Galappathi K, Mathiesen B, Nilsen K, Graff BA. Hypoxia promotes lymph node metastasis in human melanoma xenografts by up-regulating the urokinase-type plasminogen activator receptor 1. Cancer Res 2002; 62: 1847-53.

15. Ohta Y, Endo Y, Tanaka M, Shimizu J, Oda M, Hayashi Y, Watanabe Y, Sasa$\mathrm{ki}$ T. Significance of vascular endothelial growth factor messenger RNA expression in primary lung cancer. Clin Cancer Res 1996; 2: 1411-6.

16. Guerrin M, Moukadiri H, Chollet P, Moro F, Dutt K, Malecaze F, Plouët J. Vasculotropin/vascular endothelial growth factor is an autocrine growth factor for human retinal pigment epithelial cells cultured in vitro. J Cell Physiol 1995; 164: 385-94.

17. Oberg-Welsh C, Sandler S, Andersson A, Welsh M. Effects of vascular endothelial growth factor on pancreatic duct cell replication and the insulin production of fetal islet-like cell clusters in vitro. Mol Cell Endocrinol 1997; 126: 125-32.

18. Sondell M, Lundborg G, Kanje M. Vascular endothelial growth factor has neurotrophic activity and stimulates axonal outgrowth, enhancing cell survival and Schwann cell proliferation in the peripheral nervous system. J Neurosci 1999; 19: 5731-40.

19. Nakopoulou L, Stefanaki K, Panayotopoulou E, Giannopoulou I, Athanassiadou P, Gakiopoulou-Givalou H, Louvrou A. Expression of the vascular endothelial growth factor receptor-2/Flk-1 in breast carcinomas: correlation with proliferation. Hum Pathol 2002; 33: 863-70.

20. Jackson MW, Roberts JS, Heckford SE, Ricciardelli C, Stahl J, Choong C, Horsfall DJ, Tilley WD. A potential autocrine role for vascular endothelial growth factor in prostate cancer. Cancer Res 2002; 62: 854-9.

21. Tian X, Song S, Wu J, Meng L, Dong Z, Shou C. Vascular endothelial growth factor: acting as an autocrine growth factor for human gastric adenocarcinoma cell MGC803. Biochem Biophys Res Commun 2001; 286: 505-12.

22. Wang JY, Sun T, Zhao XL, et al. Functional significance of VEGF-a in human ovarian carcinoma: role in vasculogenic mimicry. Cancer Biol Ther 2008; 7: 758-66.

23. Sun T, Sun BC, Ni CS, et al. Pilot study on the interaction between B16 melanoma cell-line and bone-marrow derived mesenchymal stem cells. Cancer Lett 2008; 263: 35-43.

24. Duxbury MS, Whang EE. RNA interference: a practical approach. J Surg Res 2004; 117: 339-44.

25. Dave RS, Pomerantz RJ. RNA interference: on the road to an alternate therapeutic strategy! Rev Med Virol 2003; 13: 373-85.

26. Schiffelers RM, Ansari A, Xu J, et al. Cancer siRNA therapy by tumor selective delivery with ligand-targeted sterically stabilized nanoparticle. Nucleic Acids Res 2004; 32: 149.

27. Brummelkamp TR, Bernards R, Agami R. Stable suppression of tumorigenicity by virus-mediated RNA interference. Cancer Cell 2002; 2: 243-7.

28. Wilda M, Fuchs U, Wössmann W, Borkhardt A. Killing of leukemic cells with a BCR/ABL fusion gene by RNA interference (RNAi). Oncogene 2002; 21: 5716-24.

29. Rennel E, Waine E, Guan H, et al. The endogenous anti-angiogenic VEGF isoform, VEGF165b inhibits human tumour growth in mice. Br J Cancer 2008; 98: 1250-7.

30. Harper SJ, Bates DO. VEGF-A splicing: the key to anti-angiogenic therapeutics? Nat Rev Cancer 2008; 8: 880-7.

\section{Address for correspondence}

\section{Dr. Sun Bao-cun}

Department of Pathology

and Cancer Hospital of Tianjin

Medical University

Tianjin, 300070

PR China

phone: +8613602111192

fax: +86-022-23542527

e-mail: sunbaocun@yahoo.com.cn

Submitted: $\quad$ 19.05.2012

Accepted: $\quad$ 16.08.2012 